\title{
DIE ROL VAN DIE UNIEVERDEDIGINGSMAG IN DIE ONDERDRUKKING VAN DIE NYWERHEIDSONLUSTE VAN JANUARIE 1914
}

Maj C.J. Jacobs*

During the Railways and Mineworkers strike which commenced on the 18th of January 1914, the Union Defence Force, enlarged by the Active Citizen Force and assisted by the Commandos, were able to take immediate action and suppress the riots.

The strike was also excellent preparation of the Union Defence Force for their participation in the First World War and the suppression of the ensuing Rebellion of 1914/15. It clearly illustrated the value of an own Defence Force, in that it would no longer be necessary to make use of Imperial troops for the defence of South Africa.

\section{Inleiding}

Met die totstandkoming van die Unie van SuidAfrika in 1910 is die daarstelling van een verdedigingstelsel vir die vier voormalige kolonies in die vooruitsig gestel. Hierdie voorneme is dan ook uitgevoer met die goedkeuring van die Verdedigingswet van 1912 deur die Parlement. Tydens die nywerheidsonluste van Mei 1913 was die Unieverdeidingsmag egter nog nie gereed om op te tree nie. Gevolglik moes Imperiale troepe gebruik word om die toestand onder beheer te bring. Indien Brittanje egter in 'n Europese oorlog betrokke sou raak, was daar dalk nie genoeg troepe beskikbaar om binnelandse onrus in Suid-Afrika te help bekamp nie. Die 1913-staking het ook getoon dat die werkers goed georganiseerd was en in die toekoms die ekonomie, deur middel van verdere staking skade kon berokken. Dit het dus die noodsaaklikheid van 'n eie verdedigingsmag duidelik gedemonstreer.

Genl J.C. Smuts wou verhoed dat die stakers die regering op die verkeerde voet betrap. Hy het gevolglik as minister van verdediging 'n leidende rol gespeel om voor die einde van 1913 die Unieverdedigingsmag van die grond af te kry. Die mag is vergroot deur die totstandkoming van die Aktiewe Burgermag op 1 Julie 1913. Op die platteland het die regering ook die kommando's tot sy beskikking gehad. Toe die spoorwegen mynwerkers in Januarie 1914 staak, was die Unieverdedigingsmag dus beskikbaar om op te tree.

\section{Nywerheidsgeskille lei tot gewapende verset}

Daar het reeds in Oktober 1913 'n geskil tussen blanke spoorwegwerkers en die owerheid ontstaan oor die afdanking van personeel met die oog op kostebesparing. Spoorwegwerkers het gevolglik in Pretoria onder leiding van vakbondleiers soos H.J. Poutsma en J.T. Bain begin staak. Dit is opgevolg met stakings in al die belangrikste spoorwegsentrums in die land. Dié krisis het ernstige afmetings begin aanneem toe die blanke goudmynwerkersunie uit simpatie met die spoorwegwerkers, in Januarie 1914 ook 'n staking afgekondig het. Binne enkele dae het meer as twintigduisend Blanke werkers gestaak en die land in 'n politieke en ekonomiese krisis gedompel. ${ }^{1}$ Die stakers se hoofkwartier is ingerig in die Handelsaal (Trades Hall) in Fordsburg. Bain en sy luitenante het die staking van hier beheer en van tyd tot tyd boodskappe aan die regering gestuur waarin hulle griewe en eise uiteengesit is. ${ }^{2}$ Hulle optrede sou egter nie tot eise beperk bly nie.

Op 7 Januarie het die polisie naby die Georgetown-lokasie aan die Oos-Rand, beslag gelê op 'n halwe kis gelatien. Twee dae later het die stakers daarin geslaag om die spoorlyn vanaf Kaapstad te beskadig. ${ }^{3}$ Daar is ook op twee plekke in Krugersdorp en in Roodepoort dinamiet op die spoorlyne gevind. ${ }^{4}$ 'n Onrusbarende verskynsel het sy kop uitgesteek toe dit op 10 Januarie rugbaar geword het dat die stakers hulself in gewapende kommando's begin 
organiseer het. ${ }^{5}$ Op 11 Januarie het die stakers gepoog om treindienste in Johannesburg te ontwrig maar soldate en vrywilligers het die treine aan die loop gehou. ${ }^{6}$ Terselfdertyd het die stakers in Fordsburg 'n protesvergadering onder leiding van Bain gehou. Daar is aangedring op die vrylating van stakersleiers wat op 9 Januarie in hegtenis geneem is en dat die Unieverdedigingsmag, wat op 10 Januarie 1914 gemobiliseer is, gedemobiliseer moes word. Speurders het die vergadering in burgerlike drag bygewoon maar geen verdere insidente het plaasgevind nie. ${ }^{7}$

Verdere voorvalle van hierdie aard was op 13 Januarie die beskadiging van die spoorlyn vanaf Standerton aan die Oos-Rand en skote wat aan die Wes-Rand op ' $n$ troepetrein gevuur is. Op dieselfde dag is daar by Wonderfontein en Waterval Boven met die telegraaflyne gepeuter maar die skade was gering. ${ }^{8}$ Op 14 Januarie is die spoorlyne naby Bethlehem en Kaapstad beskadig. In Johannesburg het die polisie op dieselfde dag 3 slagdoppies en 3 stokke gelatien in 'n huis in Fordsburg gevind en onskadelik gestel. ${ }^{9}$ Veertig mense is verder gearresteer wat die vorige nag na 20 h00 op straat was. ${ }^{10} \mathrm{Op}$ dieselfde dag het die Federasie van Vakbonde 'n algemene staking uitgeroep en die krisis op 'n spits gedryf.

\section{Regeringsoptrede}

Intussen het die Johannesburgse blad, "The Star" op 6 Januarie reeds gewaarsku dat die Polisie wat beskikbaar was nie in staat sou wees om die situasie te beheer nie. Die koerant het dan ook aanbeveel dat die regering vinnig moes optree om 'n algemene gewapende opstand te voorkom. ${ }^{11}$ In der waarheid was daar teen 1914 in Suid-Afrika slegs een polisie-amptenaar per $73 \mathrm{vk}$ myl.

Aan die Witwatersrand alleen was daar 22000 blanke mynwerkers, 45000 spoorwegwerkers, sowel as ' $n$ verdere 12000 in ander ongeskoolde en semi-geskoolde beroepe. Die omvang van die gebied wat beskerm moes word was ongeveer $50 \mathrm{vk}$ myl. Afgesien van spoorlyne was daar 100 sleutelpunte wat beskerm moes word. Verder was daar 200000 swart werkers aan die Witwatersrand wat moontlik in opstand kon kom. ${ }^{12}$

Die regering is egter nie onverhoeds betrap nie. Die situasie is fyn dopgehou en die eerste stap was om te verhoed dat die stakers groot hoeveelhede wapens en ammunisie bekom. In die Buitengewone Staatskoerant van 9 Januarie 1914 is die verkoop van wapens en ammunisie in die landdrosdistrikte Johannesburg, Boksburg, Germiston, Krugersdorp, Pretoria en Middelburg vir 'n maand lank verbied. ${ }^{13}$ Vervolgens het die polisie toegeslaan en op dieselfde dag die meeste stakerleiers tydens 'n protesvergadering in Pretoria gearresteer. Hulle was, H.J. Poutsma, J.M. Nield, R.B. Waterston, J.R. Munro, W. Glendon, C. Wade, J. Campbell, en W. Livingstone.$^{14}$ J.T. Bain was egter steeds op vrye voet en het nog die staking vanaf Fordsburg beheer. Daar het soos reeds aangedui nog steeds insidente van geweld voorgekom en sterker optrede van regeringskant was dus nodig.

\section{Die mobilisasie van die unieverdedigingsmag}

Die regering het nou besef dat die verdedigingsmag betyds gemobiliseer moes word voordat ' $n$ algemene staking afgekondig word. Die staatskoerant wat die mobilisasie afgekondig het, het op 10 Januarie 1914 verskyn. Agtien eenhede is opgeroep om in Transvaal op te tree. Die meeste van hierdie eenhede was bestem vir die Witwatersrand, omdat die regering die meeste probleme daar verwag het. $^{15}$

Daar is verder ook agt kommando's in die Transvaal, 22 in die OVS, vier in Natal en twee in die Kaapprovinsie opgeroep. Die kommando's is per trein na die stedelike sentra vervoer, terwyl stedelike eenhede hulle eie vervoer gebruik het om in voorafbepaalde versamelgebiede bymekaar te kom. ${ }^{16}$ Die mobilisasie het redelik vlot verloop en alle eenhede is binne drie dae ontplooi. ${ }^{17}$ Die implikasie hiervan was dat hulle reeds in hul voorafbepaalde posisies was voordat die algemene staking op 14 Januarie 1914 afgekondig is. Die verdedigingsmag was dus gereed om op die kritieke oomblik op te tree.

Die enigste probleme wat tydens mobilisasie ondervind is was dat sestien persone geweier het om aan te meld vir diens, een persoon afwesig sonder verlof gegaan het en een persoon geweier het om sy kar en perde wat opgekommandeer is, te verskaf. ${ }^{18}$ Andersins het beide die publiek en die lede van die gewapende magte goed saamgewerk tydens die mobilisasie-fase. ${ }^{19}$ 


\section{Die organisasie en ontplooiing van die verdedigingsmag}

Met die totstandkoming van die Unieverdedigingsmag is die land in militêre distrikte verdeel. Hieraan is 'n aantal Aktiewe Burgersmageenhede toegeken.

Tydens die staking is die onlusgebiede egter in beheergebiede verdeel met ' $n$ kontrole-offisier in bevel. Die grense van die militêre distrikte en die beheergebiede het soms ooreengestem. So was die Witwatersrand byvoorbeeld militêre distrik no 8 maar beheergebied no $1 .{ }^{20}$ Die kontrole-offisiere was lede van die Suid-Afrikaanse Polisie of die SA Berede Skutters. Soos wat die situasie versleg, sou eenhede van die Aktiewe Burgersmag en die kommando's die polisie in 'n beheergebied bystaan en die bevel aan ' $n$ offisier van die verdedigingsmag oorgedra word. ${ }^{21}$

Die beheergebiede is weer onderverdeel in subgebiede en ' $n$ militêre eenheid is gewoonlik van elke sub-gebied toegeken. Die eenheidsbevelvoerders was direk aan die kontrole-offisier verantwoordelik. ${ }^{22}$ Elke man is met 50 patrone uitgereik en bevelvoerders is veral gewaarsku teen troepe wat die stakers goedgesind was. ${ }^{23}$

Wat logistiek betref, is tydelike depots op geskikte plekke, soos sportgronde, ingerig. Voorrade is per spoor na hierdie punte vervoer, vanwaar die verskillende eenhede dan bevoorraad is. Skole is selfs in sommige dorpe ontruim om as militêre hoofkwartiere te dien. ${ }^{24}$ Reëlings is ook getref om die hawepersoneel in al die hawestede te mobiliseer indien voorrade vanaf Brittanje benodig sou word. ${ }^{25}$ Probleme wat hier voorgekom het, was dat elke kontrole-gebied nie oor 'n eie administratiewe-offisier beskik het nie. Die verdedigingsmag het ook nog nie oor genoeg ander opgeleide administratiewe personeel beskik nie. In Johannesburg is byvoorbeeld te veel kos en voer aan sekere eenhede uitgereik, terwyl ander weer te min kampeeruitrusting ontvang het. In sommige gebiede moes heelwat voorrade ook inderhaas uit plaaslike bronne aangevul word. Daar is ook gevind dat daar nie genoeg gewere in die Unie beskikbaar was nie. Gevolglik is daar reëlings met die Britse regering getref vir die verskaffing daarvan. In totaal is 6600 gewere dan ook vanaf die Britse militêre owerhede in Suid-Afrika bekom. ${ }^{26}$

\section{Die klimaks: Fordsburg 15 Januarie 1914}

Die stakers se hoofkwartier in die Handelssaal te Fordsburg was die regeringsmagte se volgende doelwit. Die polisie en soldate het reeds op 13 Januarie die gebou omsingel en op die onvoorwaardelike oorgawe van die stakers aangedring. Bain het hierdie oproep egter geïgnoreer en voortgegaan met sy bedrywighede vanuit die gebou. ${ }^{27}$ Polisie en soldate het nader aan die gebou beweeg maar hulle is met geweervuur weggehou. Daarop het hulle teruggetrek na 'n veilige afstand en verdere bevele afgewag. ${ }^{28}$

Op 15 Januarie het die regering besluit om op te tree. Polisie en soldate het alle toegange tot die gebied afgekamp, terwyl 'n twaalfponder kanon van die Transvaal Horse Artillery nader gebring en op die gebou gerig is. Kol Sholto van die SA Polisie het saam met twee ander offisiere vorentoe beweeg en Bain meegedeel dat die regering die onvoorwaardelike oorgawe van die stakers eis. Indien hieraan nie gehoor gegee word nie, sou die gebou met kanonvuur bestook en bestorm word. ${ }^{29}$

Bain het waarskynlik besef dat hy nie lank teen 'n oormag weerstand sou kan bied nie en oorgegee. Die gebou was nie teen kanonvuur bestand nie, terwyl daar maar sowat 200 stakers was. Sommige van hulle was, om alles te kroon ongewapen, terwyl daar ook slegs beperkte voorrade in die gebou beskikbaar was. ${ }^{30}$ Die regeringstroepe het bestaan uit ' $n$ aantal kommando's, terwyl die Transvaal Scottish, Witwatersrand Rifles en 1 kompanie van die Rand Light Infantry binne ' $n$ kort tydsbestek op die toneel kon wees. $^{31}$

Hierna het die staking geleidelik ten einde geloop, hoewel vanaf 16 tot 30 Januarie geïsoleerde voorvalle van geweld en beskadiging van spoorlyne voorgekom het. Die krisis was teen 16 Januarie so te sê verby. Teen daardie tyd het die meeste stakers reeds begin werk. Die waarnemende uitvoerende beamptes van die Handelsfederasie en die Transvaalmynwerkersunie het op 22 Januarie in Johannesburg die staking afgelas. ${ }^{32}$ Op 23 Januarie het die polisie op 'n groot hoeveelheid springstof op die gronde van die Transvaal Estates and Development Company en die Ferreira Deep-myn beslag gelê. ${ }^{33}$ Daarmee is indiwiduele oproermakers se vermoë om nog enige probleme te veroorsaak in die kiem gesmoor en teen die einde van die maand was die land weer rustig.

\section{Die demobilisasie van die verdedigingsmag}

Die Unieverdedigingsmag is op 18 Januarie 
1914 by wyse van 'n buitengewone staatskoerant gedeeltelik gedemobiliseer. ${ }^{34}$ Twee dae later, 20 Januarie, is die kommando's in die Witwatersrand huis toe gestuur, terwyl die Aktiewe Burgermageenhede vanaf 24 Januarie ook gedomobiliseer is ${ }^{35}$ In sekere dele van die land is sommige eenhede egter steeds op 'n gereedheidsgrondslag gehou. Genl Smuts het op 18 Januarie aan Genl Beyers opdrag gegee dat die eenhede in die Witwatersrand-gebied met opleiding moes aangaan om as reserwe te dien ingeval enige verdere onluste voorkom. ${ }^{36}$

Op 11 Januarie het genl Smuts aan kol Truter, die Kommissaris van Polisie, opdrag gegee dat hy weer die pligte van die kontrole-offisier in Johannesburg moes oorneem. ${ }^{37}$ Met hierdie optrede het die Polisie weer die beheer oor die binnelandse veiligheid oorgeneem. Die unieverdedigingsmag was nou slegs op bystand indien verdere probleme ondervind sou word. Krygswet is egter eers op 11 Maart 1914 opgehef. $^{38}$ Die enigste verliese wat die verdedigingsmag gehad het was twee persone wat in skietongelukke dood is. Geen stakers is gedood agv regeringsoptrede nie. $^{39}$

\section{Slotsom}

In die geskiedenis van die Unieverdedigingsmag word die gebeure rondom die 1914-staking oorskadu deur die Rebellie en Suid-Afrika se deelname aan die Eerste Wêreldoorlog. Tog was dit ' $n$ belangrike mylpaal in die geskiedenis van die organisasie, omdat dit sy eerste optrede ter beskerming van die staatsgesag in Suid-Afrika was.

Soos aangedui was die polisiemag te klein om wet en orde te handhaaf. Die omvang van die stakers se steun en hulle bereidwilligheid om geweld te gebruik kon 'n ernstige bedreiging vir die regeringsgesag ingehou het. Alles het dus van die mobilisasiespoed en doeltreffendheid van die verdedigingsmag afgehang.

Die meeste eenhede was binne drie dae gemobiliseer en op pad na hulle ontplooiingsgebiede. ' $n$ Dag voor die amptelike afkondiging van die algemene staking op 14 Januarie 1914, was die soldate reeds in posisie en gereed vir optrede. Hierdeur het die regering die inisiatief verkry en sou die stakers se pogings nie werklik van die grond af kom nie.
Voordat die mobilisasie-order uitgereik is, het dit slegs ses dae geneem om doeltreffende stakersweerstand tot feitlik een gebied, Fordsburg, te beperk. Daarna was dit nie moeilik om die leiers te oortuig dat verdere weerstand nodeloos is nie. Met die vinnige en doeltreffende onderdrukking van die opstand in Johannesburg teen 15 Januarie 1914, het die staking in werklikheid ten einde geloop, alhoewel verspreide insidente hier en daar nog voorgekom het. Beheer oor binnelandse veiligheid kon egter reeds op 19 Januarie weer aan die polisie oorhandig word, waarna die toestand in die land gou na normaal teruggekeer het. Die administratiewe probleme wat ondervind is, byvoorbeeld met tekorte aan gewere en ammunisie, het nie 'n noemenswaardige invloed op die verloop van gebeure gehad nie. Dit kan toegeskryf word aan die normale groeipyne van 'n pasgestigte organisasie. Die verlies van twee mense deur skietongelukke was egter 'n aanduiding dat daar in die toekoms aandag geskenk sal moet word aan die toepassing van veiligheidsmaatreëls.

Die staking was 'n goeie voorbereiding vir die Unieverdedigingsmag se toetrede tot die Eerste Wêreldoorlog en die onderdrukking van die daaropvolgende Rebellie van 1914/15. Dit het ook die waarde van 'n eie verdedigingsmag gedemonstreer, deurdat dit nie langer nodig sou wees om Imperiale troepe vir die verdediging van Suid-Afrika te gebruik nie.

Maj C.J. Jacobs (B.Mil, BA Hons, Hons B.Mil) is tans 'n lektor in Krygsgeskiedenis aan die Militêre Akademie Saldanha.

\section{Bronneverwysings}

1. Kruger, D.W.: The Making of a Nation, p74.

2. SAW-Argief, Argiefgroep DC, Houer 168. Leêr 7164/1/ Telegram, Goewerneur Genl - Sekretaris van Kolonies, dd Pretoria, 13 Jan 1914.

3. SAW-Argief, Argiefgroep DC, Houer 168, Leêr 7164/7. Parlementêre Verslag, Sekretaris van Verdediging - Minister van Verdediging, dd Kaapstad, 18 Feb 1914

4. Ibid.

5. Cd 7348, Union of South Africa, Correspondence relating to the recent General Strike in South Africa, p2.

6. Ibid, pp 52-56.

7. SAW Argief, Argiefgroep DC, Houer 168, Leêr 7164/7. Parlementêre Verslag, Sekretaris van Verdediging - Minister van Verdediging, dd
Kaapstad, 18 Feb 1914.

8. Ibid.

9. Ibid.

10. SAW Argief, Argiefgroep DC, Houer 168, Leêr 7164/17/1. Situasierapport, Kontrole Offisier Johannesburg - Sekretaris van Verdediging, dd Johannesburg, 14 Jan 1914

11. The Star, 6 Jan 1914.

12. Cd 7348, Union of South Africa, Correspondence relating to the recent General Strike in South Africa, pp 109-114.

13. Buitengewone Staatskoerant van die Unie van Zuid-Afrika, no 449 , Proklamtie 8/14.

14. Cd 7348, Union of South Africa, Correspondence relating to the recent General Strike in South Africa, p 46.

15. Ibid, p91.

16. SAW-Argief, Argiefgroep DC, Houer 171, Leêr A 163/7178. Memorandum SA Spoorweë - Departement van Verdediging, dd Pretoria, 28 Feb 1914. 